Vahid Bay ${ }^{1,2}$, Naser Darakhshani², Fatemeh Bay ${ }^{3}$, Saeed Fallah, Ehsan Zarei ${ }^{4}$, Mahboobeh Asadzadeh ${ }^{2}$

${ }^{1}$ Health Management and Social Development Research Center, Golestan University of medical sciences, Gorgan, Iran ${ }^{2}$ Department of Healthcare Services Management, School of Health Management \& Information Sciences, Iran University of Medical Sciences, Tehran, Iran.

${ }^{3}$ Department of Psychology, Faculty of Humanities and Physical Education, Gonbad Kavous University, Gonbad Kavous, Iran

${ }^{4}$ Department of Management, Economics and Health Policy, School of Management \& Medical Education Shahid Beheshti University of Medical Sciences (SBMU), Tehran, Iran

\title{
Quality of diabetes care and its consequences in Northern Iran
}

\section{ABSTRACT}

Background. Diabetes is an important public health problem. This study aimed to investigate the quality of care in patients with diabetes type 2 and its consequences in rural areas at Golestan province, North of Iran, in comparison to standards of the Ministry of Health and Education of Iran and the American Diabetes Association.

Methods. This was a cross-sectional study based on data from 308 patients with diabetes type 2 in rural areas at Golestan province, which was conducted through a two-stage classified sampling method and random selection. Data of this research was gathered through a questionnaire (fulfilled by the interviewer), assessment blood sugar, and information obtained from patients' files. Data were analyzed by descriptive statistics and SPSS version 19.

Results. The mean age of patients was 57 years and 88 patients (29\%) were male. Only $35 \%$ of patients were visited seasonally by a family physician. In addition, only $24 \%$ of patients were visited at least once a year by an ophthalmologist, and $31 \%$ of patients underwent a glycated hemoglobin test at least twice a year. Influenza and hepatitis vaccines were given to $1.6 \%$ and $9.4 \%$ of patients, respectively. $85 \%$ of pa-

Address for correspondence:

Mahboobeh Asadzadeh

Department of Healthcare Services Management,

School of Health Management \& Information Sciences,

Iran University of Medical Sciences, Tehran, Iran,

e-mail: zendegan@yahoo.com

Clinical Diabetology 2021, 10; 6: 462-467

DOI: 10.5603/DK.2021.0051

Received: 30.09 .2020 tients were evaluated once a year for lipid profile and $61 \%$ for creatine and albumin. Only $31 \%$ of patients received nutrition counseling at least once a year. Controlled glycated hemoglobin $\left(\mathrm{HBA}_{1 \mathrm{c}}\right)$ was $27 \%$ and most patients were in the range of overweight and obesity (> 75\%).

Conclusion. The findings of this study showed that the quality of diabetes care and its consequences in patients is not desirable and is far from the standards provided by the Iran's Ministry of Health and the American Diabetes Association and requires revision in the current program of diabetes control. (Clin Diabetol 2021; 10; 6: 462-467)

Key words: Diabetes type 2, quality control, quality of health care

\section{Introduction}

Diabetes is the most prevalent metabolic disease worldwide and is entitled as "Latent Epidemic" by World Health Organization (WHO) [1]. This complicated chronic disease is continuously required medical care and is one of the most important urgencies for world health in the $21^{\text {st }}$ century $[2,3]$. The disease has been reported worldwide as one of the major leading causes of blindness, renal failure, heart attack, brain stroke, and lower limb amputation [4].

International Diabetes Federation estimated the number of patients with diabetes as 415 millions of individuals in 2015, and according to the prediction of WHO, diabetes is the seventh cause of mortality in $2030[2,4]$. The prevalence of diabetes around the world increased from $4.7 \%$ in 1998 to $8.5 \%$ in 2014 
(in individuals aged more than 18 years), and this represents an increase in the prevalence of diabetes in the world. In addition, International Diabetes Federation estimated the prevalence of diabetes as 8.5\% in 2015 in Iran (in individuals aged 20-79 years), and according to provincial reports the prevalence of this disease in Golestan province is also estimated as $10 \%$ (in individuals aged more than 18 years) $[5,6]$. However, the prevalence of diabetes in low- and moderate-income countries is increasing rapidly, and if a correct attempt has not been made for prevention of the disease, it is estimated that by 2040, nearly 642 million individuals will be affected by diabetes [2].

According to the report by $\mathrm{WHO}$ diabetes is treatable and the complications are avoidable or delayed by diet, physical activity, medication, and screening as a routine [4]. Research has shown that a $1 \%$ reduction in glycated hemoglobin $\left(\mathrm{HBA}_{1 \mathrm{c}}\right)$ reduces the risk of complications of diabetes by up to $40 \%$ [7]. But unfortunately, many studies investigated the control and care of diabetes in different countries especially in Iran, mostly indicate that the status of care and control of diabetes is not desirable [8-16].

There is no doubt today that improved blood glucose control in patients with diabetes can reduce the incidence of chronic complications, and also blood pressure, cholesterol, triglyceride, and body mass index (BMI) of these patients should be in an optimum range and based on the international standards in order to prevent the complications [10]. In this regard, the most comprehensive international standards for the care and treatment of patients with diabetes are published by American Diabetes Association and American Association of Clinical Endocrinology, and the Institute of Endocrinology include standards of care which are updated annually based on the quality of new evidence, and the cost of many of these attempts has also been identified [3].

In our country, the national program for prevention and control of diabetes type 2, with the main purpose of prevention and control of diabetes and its complications, has been integrated into the family physician program of rural areas in our country in 2004 and is running. Therefore, this study aimed to investigate the quality of care in patients with diabetes type 2 and its consequences (controlled glucose level) in rural areas at Golestan province.

\section{Methods}

This was a cross-sectional study conducted between April 2018 and April 2019 based on data of 340 patients with diabetes type 2 which was conducted through a two-stage classified sampling method and
Table 1. Mean glycated hemoglobin in participants

\begin{tabular}{cccc}
\hline Variable & Cut point & Unit & Percent of patient \\
\hline $\mathrm{HbA}_{1 \mathrm{c}}$ & $\leq 7$ & $\%$ & 26.6 \\
& $\leq^{*}$ & $\%$ & 33.8
\end{tabular}

*Considering $\mathrm{HbA}_{1 \mathrm{c}} \leq 8$ for elder patients, with severe complications of diabetes, heart, vascular and renal co-morbidities, and $\mathrm{HbA}_{1 \mathrm{c}} \leq 7$ for other patients

the participants were recruited randomly (classified peroration). The population of this study consisted of 2400 patients with diabetes type 2 who were covered by the national prevention and control program of diabetes at 19 rural health and treatment centers of Golestan province and medical files were recorded for them.

The inclusion criteria were patients with diabetes type 2, at least one year after treatment began, age more than 20, availability of required documents in patient's file during past one year, and willingness to cooperate.

This study was performed in two consecutive stages. At the first stage, all the patients were assessed for glycated hemoglobin and BMI by the trained experts in order to evaluation of diabetes control status, and then at the second stage, data related to rate and quality of provided care were extracted from the recorded data in paper and electronic files of the patients, and also questionnaire (fulfilled by the interviewer).

For measuring glycated hemoglobin $5 \mathrm{cc}$ of blood was collected and the blood samples were transferred to the central laboratory of each city in 2 hours and were evaluated by Auto-analyzer system BT1500. Weight was measured by a digital scale with minimum cloth wearing and height was measured by a wall height-meter. Obtained data was entered by SPSS software Version 19 and was analyzed by descriptive statistics.

\section{Results}

In this study out of 340 individuals, 308 individuals entered the final analysis, and the percentage of response was $91 \%$. Out of 308 participants in this study, 88 individuals were men (29\%), and the mean age of them was $57 \pm 15$ years, and minimum and maximum ages were 24 and 86 years, respectively.

Mean glycated hemoglobin in participants was 8.1 $\pm 1.7 \%$. The mean BMI was $29 \pm 6 \mathrm{~kg} / \mathrm{m}^{2}$ and more than $78 \%$ of patients were in the range of overweight and obesity. Table 1 shows the mean glycated hemoglobin in participants.

Due to care provided for patients, a glycated hemoglobin test $\left(\mathrm{HbA}_{1 \mathrm{c}}\right)$ was performed for each individual 
Table 2. frequency of care performed for patients

\begin{tabular}{lc}
\hline Type of care & $\begin{array}{c}\text { Percentage } \\
\text { of patients }\end{array}$ \\
\hline $\begin{array}{l}\text { Performing visits by physician at least } \\
4 \text { times per year }\end{array}$ & 35 \\
$\begin{array}{l}\text { Providing care by rural health providers } \\
\text { at least } 4 \text { times per year }\end{array}$ & 91.9 \\
$\begin{array}{l}\text { Providing care by rural health providers } \\
\text { at least } 12 \text { times per year }\end{array}$ & 19.5 \\
$\begin{array}{l}\text { Performing ophthalmology examination } \\
\text { at least once a year by an ophthalmologist }\end{array}$ & 23.7 \\
$\begin{array}{l}\text { Performing mental health consultation } \\
\text { at least once a year by psychologist } \\
\text { or family physician } \\
\begin{array}{l}\text { Performing nutrition consultation } \\
\text { at least once a year by a dietician }\end{array}\end{array}$ \\
\hline
\end{tabular}

Table3. Frequency of tests performed for patients

\begin{tabular}{|c|c|}
\hline $\begin{array}{l}\text { Type laboratory test done } \\
\text { for the patients }\end{array}$ & $\begin{array}{l}\text { Percentage } \\
\text { of patients }\end{array}$ \\
\hline $\begin{array}{l}\text { Performing glycated hemoglobin } \\
\text { test at least twice a year }\end{array}$ & 30.8 \\
\hline $\begin{array}{l}\text { Performing glycated hemoglobin } \\
\text { test at least once a year }\end{array}$ & 60.1 \\
\hline Performing FBS test at least 4 times a year & 28 \\
\hline $\begin{array}{l}\text { Measuring blood pressure at least } 4 \text { times } \\
\text { a year }\end{array}$ & 89 \\
\hline $\begin{array}{l}\text { Measuring blood pressure at least } 12 \text { times } \\
\text { a year }\end{array}$ & 33.1 \\
\hline $\begin{array}{l}\text { Measuring body mass index at least } 4 \text { times } \\
\text { a year }\end{array}$ & 21.8 \\
\hline $\begin{array}{l}\text { Measuring body mass index at least } 12 \text { times } \\
\text { a year }\end{array}$ & 8.1 \\
\hline $\begin{array}{l}\text { Performing lipid profile test at least once a } \\
\text { year }\end{array}$ & 85.7 \\
\hline $\begin{array}{l}\text { Performing creatine and albumin test at least } \\
\text { once a year }\end{array}$ & 61 \\
\hline
\end{tabular}

on average $1.2 \pm 1.5$ times a year (at minimum 0 times and maximum 12 times). Table 2 shows the frequency of care provided by health center staff and Table 3 presents the frequency of tests performed for patients.

The study also found that only 29 patients received the hepatitis vaccine. Table 4 shows the frequency of vaccinated patients.

\section{Discussion}

Diabetes is one of the important metabolic diseases, which due to its growing prevalence has be-
Table 4. Frequency of vaccinated patients

\begin{tabular}{lc}
\hline Type of vaccinated patients & $\begin{array}{c}\text { Percentage } \\
\text { of patients }\end{array}$ \\
\hline Patients who received hepatitis vaccine & 9.4 \\
Patients who received influenza vaccine & 1.6 \\
during last year & \\
\hline
\end{tabular}

come one of the important challenges that health and treatment staff over the various countries including developing and developed ones were faced [10]. In the current study, 220 participants (71\%) were women. in the domestic conducted studies this percentage was between $62-81 \%[9,17,18]$. In the Middle East also the women were most affected by the disease than men. It can be said that a sedentary lifestyle in women is one of the leading causes of this issue [2]. In the current study, controlled glycated hemoglobin was 27 percent. Our results also showed that the mean BMI of patients was $29 \mathrm{~kg} / \mathrm{m}^{2}$, and more than $78 \%$ of patients were in the range of overweight and obesity. In comparison to conducted domestic and foreign studies, it can be claimed that controlled lipid in our study region was close to the conducted studies at the country and Asian countries, but in comparison to determining standards by the American Diabetes Association and Ministry of Health in our country is not desirable, and overweight and obesity are also prevalent in patients as shown by the domestic studies $[9,17]$. The status of blood pressure control of patients was desirable and close to therapeutic standards determined by the Ministry of Health and Treatment and the American Diabetes Association.

Evaluation of glycated hemoglobin as the main index of diabetes care is considered and advised. All diabetic patients with stable status should be evaluated for glycated hemoglobin at least twice a year. American Diabetes Association (ADA) and Iran's Ministry of Health determined the value less than $7 \%$ as acceptable for this index in patients $[3,19,20]$.

In the current study, only $26.6 \%$ of patients had controlled blood glucose (less than 7\%), and less than $31 \%$ of the patients were assessed for glycated hemoglobin at least twice a year. In consistent Iranian studies, the controlled glycated hemoglobin was 21, 27, and $24 \%$, respectively $[9,10,21]$, and the proportion of the patients who were for this test at least twice a year was less than 33\% [22]. In addition, the controlled glycated hemoglobin in Arabic countries same Saudi Arabia, United Arabic Emirates, and Oman was between 29.3-46\% [23], and in the studies performed in China, 
America, and Sweden, this index was 40, 50, and $88 \%$, respectively [16, 24, 25].

Since the main goal for treatment and metabolic control of diabetes is the maintenance of glycated hemoglobin in the normal range, it can be said that level and quality of blood glucose control in rural areas of Golestan province is not desirable as other conducted studies in rural areas of our country and differs from therapeutic standards of American Diabetes Association and national standards of our country.

Another essential criterion that must be considered in the care of diabetic patients is measuring lipid profile. ADA recommended that lipid profiles should be evaluated for diabetic patients annually [3]. In the current study, $86 \%$ of the patients were at least once assessed for HDL-C and LDL-C. In vernacular conducted studies this rate was $20-32 \%[9,17,18]$ and in the study performed in India, $32 \%$ of patients were assessed for cholesterol [26]. Therefore, it is concluded that the rate of evaluation of HDL and LDL in the study patients was better than the vernacular average and was close to international standards. In addition, our study showed that only $45 \%$ of patients were assessed for triglyceride, whereas in another study in our country, $60 \%$ of patients were assessed in this regard [17], which showed that the rate of assessment of TG in patients in rural regions of province differs from international and national advised standards.

When blood glucose remains at a high level, it causes damage to many vessels (such as vessels of the heart, eyes, and kidneys) and also nerves [2]. According to advice by ADA, patients with diabetes type 2 must be screened annually for nephropathy and microalbuminuria [3]. In the current study, $61 \%$ of patients were assessed at least once in regard to kidneys' health. This index in the similarly conducted studies in the country was between $6-71 \%[9,17,22]$. In the study by Adman et al. in America 30\% of patients were assessed for microalbuminuria [27]. We can claim that in comparison to vernacular conducted studies the status of diabetic patients of the province was desirable in regard to renal complications, but differs from national and international standards.

The diabetic eye is directly caused by a high level of blood glucose and causes damage to the retinal capillaries, and it might lead to a reduction in vision and finally blindness [2]. In addition, it is estimated that more than $90 \%$ of diabetic patients that their blood glucose is not controlled, 5-15 years after diagnosis, experiences clinical evidence of underlying retinopathy [9]. In the guideline by ADA annual ophthalmologic examination is advised [3]. In the current study, only $23.7 \%$ of patients were examined for the health of the eyes. In the other national studies, this rate was between $20-69.9 \%$ [9, 17, 18, 22]. Due to the difference in the range of rate of provided care to patients in similar studies, it can be said that Golestan province is poor in regard to eye care, and differs from international standards.

Wounds of the foot are of most important complications of diabetes, which the probability of incidence during the lifetime of each patient is approximately $15 \%$, and a considerable percentage of these patients underwent amputation surgeries. The reason for $50 \%$ of hospitalizations in England is a diabetic foot ulcer. The prevalence of diabetic foot ulcers for patients is between $5.3-10.5 \%$ [9]. In the current study, $28 \%$ of patients were examined for foot ulcers annually and $10 \%$ of them were examined seasonally. According to advice by American Diabetes Association, foot examination should be done for diabetic patients in each visit [3]. Therefore, due to advice on visits seasonally by the family physician in diabetes prevention and control programs in rural regions, providing care for examination of the foot is not desirable.

The studies showed that a $10 \mathrm{~mm} \mathrm{Hg}$ reduction in systolic blood pressure results in a $2 \%$ reduction in risk of each diabetes complication and a $15 \%$ reduction in risk of mortality caused by diabetes [9]. In the current study blood pressure was evaluated annually for $97 \%$ of patients and seasonal for $89 \%$ of patients by a physician and health care provider. This data was partially in line with advice by the Ministry of Health and Medical Education (MOHME) of our country, indicating monthly measuring of blood pressure by the health care provider, and seasonal measurement by a physician and the advice by ADA, indicate blood pressure measurement in each visit. According to advice by the Ministry of Health of our country in order to achieve the goals of diabetes control and prevention program, integrated into family physician program of rural regions, the patients should be care provided at least season by family physician and monthly by the health care provider.

In the current study, only $35 \%$ of patients were visited seasonally by a family physician. In addition, $92 \%$ of patients were care provided seasonally, and $19.5 \%$ monthly by the health care provider. In national performed studies, between $69-86 \%$ of patients were care provided by their physician during the last year $[10,18]$. Due to care standards by the Ministry of Health and Treatment of our country, it can be said that care of patients in this province in comparison to similar studies was better, but differs from standards by MOHME and was not desirable.

Diabetic patients may be at greater risk of developing hepatitis B infection due to contact with con- 
taminated blood or the use of inappropriate equipment (blood sugar monitoring devices or contaminated needles), and also Influenza is more common in vulnerable populations, including young people, the elderly, and people with chronic diseases and is associated with mortality and morbidities. Therefore, ADA advised that patients with diabetes should be vaccinated against hepatitis B and influenza [3]. Our study showed that only $9 \%$ of patients were vaccinated against hepatitis B and $1.6 \%$ were vaccinated against influenza. In a study in America, $58 \%$ of the patients received the influenza vaccine [28]. Our results showed that the rate of coverage of influenza and hepatitis $B$ vaccination in patients with T2DM differs from standards by ADA.

For many people with diabetes, the challenging part of the treatment plan is to determine how to eat and follow the diet. Nutrition therapy has an integral role in the overall management of diabetes, and every person with diabetes must actively participate in training, self-management, and treatment planning with their healthcare team, including participating in the development of their individual diet plan. Therefore, ADA recommended that all the patients receive nutrition consultation annually [3], Our study shows that nutrition consultation was done $0.73 \pm 1.6$ times (minimum of zero and maximum of 9 times) on average for each person during one year by dietician or internist, and $31 \%$ of the patients received nutrition consultation at least once a year which differs from the mentioned standard.

Complicated environmental, social, behavioral, and emotional factors that were known as psychological factors, affect life and achievement of satisfactory results on the medical sector and mental well-being of patients with both types of diabetes.

Therefore, patients with diabetes and their families were challenged with complicated and multifaceted concerns at the initiation time of integration of diabetes care into their daily life. Therefore, ADA recommends that all the patients should be assessed on mental aspects at each visit [3]. The results of our study showed that mental health consultation was on average done for each person $0.32 \pm 0.9$ times annually (minimum zero and maximum 6 times) by psychologist or family physician, and only $17 \%$ of the patients received at least one session of mental health consultation annually, which differs from mentioned standards.

This study faced some limitations, which the researchers tried to manage with mentioned approaches. The first limitation of this study was the lack of proper cooperation of patients during stages of study due to the overlap of the study time period with the agricultural season in the rural areas of the province, which sought to justify and encourage patients on the importance of the research and using flexible scheduling to invite patients to cooperate properly.

The second limitation was the illegibility of some medical records, which a deliberate strategy was taken to obtain consultative and technical advice from the medical staff of the study center and to randomly replace the illegible file with the new one.

\section{Conclusion}

The findings of this study showed that quality of care and controlled glucose level of patients, performing laboratory tests, and periodic and annually care of patients, despite partial consistency with vernacular studies, is not desirable, and differs from standards of MOHME of our country and proposed standards by American Diabetes Association, and requires revision in the current program of diabetes control.

\section{Declarations}

\section{Ethics approval and consent to participate}

This research was approved with the ethical code of 1396,276 by the ethics committee of the Golestan University of Medical Sciences. The consent we obtained from study participants was written. We confirmed that all methods were carried out in accordance with relevant guidelines and regulations. The consent was obtained from all participants or their legal guardians.

\section{Acknowledgments}

The authors appreciate cooperation by the health deputy of Golestan University of Medical Sciences and staff and managers of health and treatment networks of cities of the province.

\section{REFERENCES}

1. AlaviNia M, Ghotbi M, Hazaveh AM, Kermanchi J, Esfehani AN, Ahmadi SY. National program for prevention and control of type 2 diabetes in urben areas. Tehran: sepid barg; 2012; 1-71.

2. Federation I. IDF Diabetes Atlas Eighth Edition 2017.International Diabetes.

3. American Diabetes Association. Standards of Medical Care in Diabetes 2019. Diabetes Care. 2019;42:S81.

4. World Health Organization. Facts Sheets. http://who.int/mediacentre/factsheets/fs312/en/.

5. Ministry of Health and Medical Education. Golestan University of Medical Sciences. prevalence of diabet in golestan province. 2017 May 29.

6. Bay V, Asl IM, Hezaveh AM, et al. Factors associated with control of type 2 diabetes mellitus in North Iran. Clinical Diabetology. 2020; 9(6): 426-432, doi: 10.5603/dk.2020.0061.

7. Ghazanfari Z, Niknami S, Ghofranipour F, et al. Determinants of glycemic control in female diabetic patients: a study from Iran. Lipids Health Dis. 2010; 9: 83, doi: 10.1186/1476-511X-9-83, indexed in Pubmed: 20701805.

8. Fallah S, Rostamzadeh S. Success of the Family Practice Plan in Diabetes Control. Journal of Health. 2016; 7(4): 417-24. 
9. Khazaei S, Saatchi A, Mirmoeini R, Bathaei SJ. Assessing Treatment and Care in Patients with Type 2 Diabetes in Rural Regions of Hamadan Province in 2013. Scientific Journal of Hamadan University of Medical Sciences. 2015; 21(4): 318

10. Delpisheh A, Azizi H, Dantalab Es, et al. The quality of care and blood suger control in type 2 diabetic patients of rural areas under the care by family physicians. Iranian Journal of Diabetes and Metabolism. 2016; 14(3): 189-98.

11. Al-Kaabi J, Al-Maskari F, Saadi $\mathrm{H}$, et al. Physical activity and reported barriers to activity among type 2 diabetic patients in the United arab emirates. Rev Diabet Stud. 2009; 6(4): 271-278, doi: 10.1900/RDS.2009.6.271, indexed in Pubmed: 20043039.

12. Al Balushi KA, Al-Haddabi M, Al-Zakwani I, et al. Glycemic control among patients with type 2 diabetes at a primary health care center in Oman. Prim Care Diabetes. 2014; 8(3): 239-243, doi: 10.1016/j.pcd.2014.01.003, indexed in Pubmed: 24472420.

13. Alsulaiman TA, Al-Ajmi HA, Al-Qahtani SM, et al. Control of type 2 diabetes in King Abdulaziz Housing City (Iskan) population, Saudi Arabia. J Family Community Med. 2016; 23(1): 1-5, doi: 10.4103/2230-8229.172221, indexed in Pubmed: 26929722.

14. Ghorbani Be, Yazdanbood A, et al. Amini Sa, Quality of care in 100 diabetic patients in a diabetes clinic in Ardabil. Journal of Ardabil University of Medical Sciences. 2012; 12(3): 239-247.

15. Mahmood MI, Daud F, Ismail A. Glycaemic control and associated factors among patients with diabetes at public health clinics in Johor, Malaysia. Public Health. 2016; 135: 56-65, doi: 10.1016/j. puhe.2015.07.043, indexed in Pubmed: 26976488.

16. Yue J, Mao X, Xu K, et al. Prevalence, Awareness, Treatment and Control of Diabetes Mellitus in a Chinese Population. PLoS One. 2016; 11(4): e0153791, doi: 10.1371/journal.pone.0153791, indexed in Pubmed: 27096738.

17. Amini M, Mehdigoya M, Delavaei A, et al. Quality of diabetic management in Iran in 2004-2006. Journal of Medical Council of Islamic Republic of IRAN. ; 2008: 20-29.

18. Montazem SH, Soleimani A, Hosseini $\mathrm{SH}$, et al. Care quality of patients with diabetes type 2 in the rural areas of Malekan, Iran. Journal of North Khorasan University of Medical Sciences. 2011; 3(3): 75-82, doi: 10.29252/jnkums.3.3.75.
19. Larijani B. Iranian National Service Framework for Diabetes. Tehran: Aftab Andisheh. 2016.

20. Larijani B. Nasli Esfehani A. Diabetes clinical guidline. Tehran: Noavaran sina. 2014

21. Hashemi Nazari S, Bigdelli MA, Khodakarim S, Brodati H. Estimating the effect of direct and indirect factors on glycemic control in type 2 diabetic patients by path analysis. Iranian Journal of Diabetes and Metabolism. 2016;15(6):351-61.

22. Iranparvar Al, Yazdanbood AA. Islam Panah S, , M S. Quality of care in100diabetic patients in a diabetes clinic in Ardabil. Ardabil J Med Sci. 2012; 12(3): 239-47.

23. Alramadan MJ, Afroz A, Hussain SM, et al. Patient-Related Determinants of Glycaemic Control in People with Type 2 Diabetes in the Gulf Cooperation Council Countries: A Systematic Review. J Diabetes Res. 2018; 2018: 9389265, doi: 10.1155/2018/9389265, indexed in Pubmed: 29682584.

24. Takahashi PY, St Sauver JL, Finney Rutten $\sqcup$, et al. Health outcomes in diabetics measured with Minnesota Community Measurement quality metrics. Diabetes Metab Syndr Obes. 2015; 8: 1-8, doi: 10.2147/DMSO.S71726, indexed in Pubmed: 25565873.

25. Husdal R, Thors Adolfsson E, Leksell J, et al. Associations between quality of work features in primary health care and glycaemic control in people with Type 2 diabetes mellitus: A nationwide survey. Prim Care Diabetes. 2019; 13(2): 176-186, doi: 10.1016/j. pcd.2018.11.005, indexed in Pubmed: 30545793.

26. Nagpal J, Bhartia A. Quality of diabetes care in the middle- and high-income group populace: the Delhi Diabetes Community (DEDICOM) survey. Diabetes Care. 2006; 29(11): 2341-2348, doi: 10.2337/dc06-0783, indexed in Pubmed: 17065665.

27. Edelman D, Olsen MK, Dudley TK, et al. Quality of care for patients diagnosed with diabetes at screening. Diabetes Care. 2003; 26(2): 367-371, doi: 10.2337/diacare.26.2.367, indexed in Pubmed: 12547864.

28. Wang J, Thomas J, Byrd D, et al. Status of diabetes care among community pharmacy patients with diabetes: analysis of the Medical Expenditure Panel Survey. J Am Pharm Assoc (2003). 2010; 50(4): 478-484, doi: 10.1331/JAPhA.2010.08173, indexed in Pubmed: 20621865. 